\title{
Article
}

\section{Judaism, Enlightenment, and Ideology}

\author{
Randi Lynn Rashkover
}

Department of Religious Studies, William \& Mary, Williamsburg, VA 23185, USA; rlrashkover@wm.edu

\begin{abstract}
The co-existence of Enlightenment and ideology has long vexed Jews in modernity. They have both loved and been leary of Enlightenment reason and its attending scientific and political institutions. Jews have also held a complex relationship to ideological forms that exist alongside Enlightenment reason and which have both lured and victimized them alike. Still, what accounts for this historical proximity between Enlightenment and ideology? and how does this relationship factor into the emergence of modern anti-Semitism? Can Jewish communities participate in contemporary societies committed to scientific developments and deliberative democracies and neither be targeted by totalizing systems of thought that eliminate Judaism's difference nor fall prey to the power and seduction of ideological forces that compete with the Jewish life-world? This article argues that Hegel's discussion of the Enlightenment in the Phenomenology of Spirit as a social practice of critical common sensism provides an immanent critique of Max Horkheimer's and Theodore Adorno's analysis of the absolutism of the Enlightenment that can bolster Jewish communal and philosophical hope in the commensurability between Judaism and the contemporary expressions of Enlightenment reason, even if it does not fully eradicate the challenges presented by ideology for Jewish communities and thinkers.
\end{abstract}

Keywords: ideology; enlightenment; Judaism; science; modernity

\section{Enlightenment and Ideology}

It is often said that there are two Americas. Most recently, this applies to the paradox of an America that rests and relies on Enlightenment institutions, e.g., science, the academy, and the system of checks and balances, and an America that appears trapped by ideological narratives that thwart democratic processes and sustain cultural polemics. What is the relationship between these two forces? How and why can Enlightenment co-exist with ideology insofar as ideology distorts or blunts reasoning processes at work in key scientific, academic, and political institutions?

The co-existence of Enlightenment and ideology has long vexed Jews in modernity. They have both loved and been leary of Enlightenment reason and its attending scientific and political institutions. As Terry Eagleton has demonstrated, the history and development of the term "ideology" is complex. Nonetheless, in this article, by "ideology", I mean a profile of a single and absolute form of rationality manifest in the determination of a fixed web of ideas that apparently follow with the force of logic but which deny contradictions and the potential validity of challenges to its self-evidence. Jews have also held a complex relationship to ideological forms such as capitalism and fascism that exist alongside Enlightenment reason and which have both lured and victimized them alike. Still, what accounts for this historical proximity between Enlightenment and ideology? and how does this relationship factor into the emergence of modern anti-Semitism? Can Jewish communities participate in contemporary societies committed to scientific developments and deliberative democracies and neither be targeted by totalizing systems of thought that eliminate Judaism's difference nor fall prey to the power and seduction of ideological forces that compete with the Jewish life-world?

In 1944, during the height of Nazi and Stalinist fervor, Theodore Adorno and Max Horkheimer composed the Dialectic of the Enlightenment as an attempt to answer this 
question. The book offers an unsettling account of the alienating and destructive outcomes of a modern reason that lends itself to distortion as ideology when exploited by ruling classes on the one hand and yet is inevitably fated to its own self-destruction, thereby opening the doors to political and economic forces ready to exploit the vacuum of social coordination left in the wake of reason's demise on the other hand. Horkheimer and Adorno's account of the dialectic of the Enlightenment has been highly influential. Its legacy appears in its impact on the Frankfurt School. Additionally, it has cleared the way for the emergence of a post-modern relativism in the wake of its diminished profile of modern reason.

In recent decades, there has been an attempt to appeal to the work of Georg Wilhelm Friedrich Hegel to reverse this tide and introduce a refortified view of reason both within philosophy in general and in Jewish thought in particular. Nonetheless, neither contemporary philosophers nor Jewish thinkers who have reintroduced the importance of Hegel's post-Kantian account of reason have assessed whether it can contend with the challenge of ideology recognized by Horkheimer and Adorno. If, as I will discuss, the Dialectic of Enlightenment leaves readers without a persuasive account of how Enlightenment reason can withstand the forces of ideology, contemporary scholarship on Hegel has neglected to demonstrate how Hegel's more robust discussion of reason offers a more powerful alternative.

The stakes of an encounter between Hegel's account of reason and ideological forces are high for Jewish communities and thinkers since the latter's confidence in the project of reconciling Judaism and modernity hangs in the balance. In what follows, I will argue that Hegel's discussion of the Enlightenment in the Phenomenology of Spirit as a social practice of critical common sensism can be enlisted as an immanent critique of Horkheimer and Adorno's analysis of the absolutism of the Enlightenment that can bolster Jewish communal and philosophical hope in the commensurability between Judaism and the contemporary expressions of Enlightenment reason. This is not to say, however, that Hegel's immanent critique eradicates the challenges presented by ideology for Jewish communities and thinkers. This is because, communal justificatory praxis, the primary outcome of Hegel's immanent critique of Horkheimer and Adorno's dialectic of Enlightenment is a fragile activity, particularly in times of life-world crises. It is precisely in the moments when rational reflection is most in demand that it is most burdensome to those who need it and therefore most likely to be challenged by forces of ideology that threaten to replace it as the mechanism for social coordination and institutional legitimization. Since, as I will argue, this is the situation affecting many Jewish communities today, Jewish thinkers are called to identify and acknowledge the unique character of the antagonism between the exercise of a Jewish communal justificatory practice that is needed for Jewish communities to remain active participants in the contemporary Enlightenment institutions of science, democracy, and the academy and the ideological forces that threaten to replace this communal practice of reflection.

\section{Dialectic of the Enlightenment}

Few works have done more to shape the contemporary understanding of the Enlightenment than Horkheimer and Adorno's Dialectic of the Enlightenment. Generally speaking, their analysis dampened 21st century hopes of reviving the philosophical contributions of the Enlightenment.

The Dialectic of Enlightenment begins with Horkheimer and Adorno's description of the Enlightenment impulse towards mastery over the contingencies of nature and history. While Horkheimer and Adorno maintain that the human quest for knowledge has long displayed the drive for control, the Enlightenment era derived unique inspiration from the Baconian confidence in "the happy match between the mind of man and the nature of things" (Horkheimer and Adorno 2002). Enlightenment, Horkheimer and Adorno argue, embraces knowledge as power. Through its tools of deductive logic, calculation, and mathematical law, the Enlightenment "man of science knows things ... to the extent that 
their 'in-itself becomes 'for him' ... In their transformation the essence of things is revealed as always the same, a substrate of domination" (Horkheimer and Adorno 2002 )

Enlightenment's claim to sovereignty over reality is linked to its perception of itself as absolute knowledge. From its perspective, the battle against the unknown has been won. The certainty of its knowledge appears in its logical "chains of inference and dependence [and in] the subordination and coordination of concepts" illustrated by the "deductive form of science" (Horkheimer and Adorno 2002) and the identification of thought with mathematics. Consequently, Enlightenment insists that speculation about merely "intelligible worlds" is "senseless prattle" (Horkheimer and Adorno 2002). Emboldened by its knowledge, Enlightenment critiques all other ideas or concepts that have not yet been understood in terms of its own calculations. Enlightenment, they say, is the "endless process ... by which ... [and] with ineluctable necessity, every definite theoretical view is subjected to the annihilating criticism that it is only a belief ..." (Horkheimer and Adorno 2002). Ideas that cannot be reduced to its terms are thereby considered the products of fantasy or superstition "and must be viewed with suspicion" (Horkheimer and Adorno 2002).

Much of the Dialectic of Enlightenment is devoted to unveiling the negative consequences of the Enlightenment as absolute knowledge. For example, originally recognized as an endorsement of the individual's capacity to think for herself, the Enlightenment's insistence upon its ability to pre-emptively achieve knowledge suppresses the individual's drive towards inquiry. From its own perspective as absolute knowledge, there is nothing new to be known, only equations and laws to apply. The delicate relationship between inquiry and a changing world is ignored, and "thought is reified as an autonomous, automatic process, aping the machine it has itself produced, so that it can finally be replaced by the machine" (Horkheimer and Adorno 2002).

Furthermore, as an instrument that suppresses human reflection, Enlightenment is easily packaged and deployed as ideology to serve the interests of a ruling class. By "ideology" I mean a profile of a single and absolute form of rationality manifest in the determination of a fixed web of ideas that apparently follow with the force of logic or what Terry Eagleton describes as an "excessive rationalism" (Eagleton 2014). As Hannah Arendt explains, an ideology is an instrument of "explanation" vis a vis a fixed account of the relationship of propositions that refuses to be "interrupted by ... [either] a new idea or a new experience" (Arendt 1953) and which therefore presents itself and is taken by many to be an absolute and utterly natural or self-evident account of the way things are. In Karen Ng's terms, ideologies are "at once social practices and forms of rationality that destroy the relation between life and self-consciousness ... [As such, ideologies are fixed constellations of ideas that are] locked within their own abstract space, as divorced from reality as a psychotic" (Ng 2015). Thus, ideologies deny the existence of their own contradictions and/or deny the validity of challenges to their self-evidence that emerge from new experiences or outside considerations. Instead they "speciously resolv[e] their conflicts and contradictions" (Ng 2015).

More specifically, Horkheimer and Adorno link Enlightenment as ideology to ruling powers. This is not surprising since Horkheimer and Adorno maintain that Enlightenment is rooted in the social reality of power inequalities. Like Durkheim, Horkheimer and Adorno recognize the "social character of intellectual forms" (Horkheimer and Adorno 2002). However, Horkheimer and Adorno maintain that social conformity is a result of coercive power. Ever since its ancient form as Homerian myth, Enlightenment has been a tool used by tyrants to secure the division of labor that guarantees their privilege. Ruling minorities who endorse Enlightenment peddle the message that knowledge is tantamount to explanation. Its reach is all comprehensive, and its findings have the absolute certainty of the deductive premises from which they follow. Technically speaking, Horkheimer and Adorno are correct to link ideologies with ruling powers, since ideologies are an attempt to silence voices that challenge the picture of rationality presented as absolute asserted by either a tyrant, a class, or a large group of persons who share social interests and seek 
to disregard the prospect of competing accounts of experiences or aspects of reality that expose contradictions or inconsistences in the ideology.

Stated otherwise, Enlightenment as ideology, Horkheimer and Adorno argue, arises from the fear of contingency. Ruling powers (like all people) are prone to this anxiety given their impulse towards preserving control. According to Horkheimer and Adorno, an Enlightenment model of knowledge and its accompanying message that the purpose of human life is self-preservation through control and mastery of reality offers ruling classes an ideological tool to quell their own insecurity and suppress the instinct in others to engage with mystery, the unknown, or the merely possible.

Moreover and equally important, Enlightenment as ideology offers a substitute for the social cohesion or coordination that can be otherwise generated by social and rational processes of responding to a shared world. As Horkheimer and Adorno explain, "by subordinating life in its entirety to the requirements of its preservation, the controlling minority guarantees, [along] with its security, the continuation of the whole" (Horkheimer and Adorno 2002). In this way, "power", they say, "confronts the individual as the universal" (ibid.), and the individual accepts this account of the universal and the purpose of her life as a participant in its apparently self-evident laws because it offers her a way to participate in society and benefit from its means of social coordination.

The immediate correlation between Enlightenment and ideology in Horkheimer and Adorno's profile of modern reason leads to alienation since Enlightenment's mastery over contingency nullifies human beings' ongoing encounter with their changing world. As Horkheimer and Adorno explain, in Enlightenment, "human beings purchase the increase in their power with estrangement from that over which it is exerted" (Horkheimer and Adorno 2002). Alienated from their world, persons are also alienated from each other since all aspects of reality are objectified and de-humanized.

The link between Enlightenment and ideology hereby established by Horkheimer and Adorno is particularly problematic for Jews since they identify a direct connection between Enlightenment and anti-Semitism. In their analysis, the link between Enlightenment and anti-Semitism is a result of problems that necessarily arise from Enlightenment's impulse to master reality through a fixed world-view that, to sustain its force, must thwart all challenges to its absolute validity. As an approach to knowledge inevitably linked to a particular group, Enlightenment has a vested interest in veiling, neglecting, and/or providing specious answers to contradictions, problems, and/or potential experiential or epistemological falsifications of its fixed map of reality. Consequently, Enlightenment in Horkheimer and Adorno's account is devoid of non-polemical mechanisms for contending with the problems or contradictions that inevitably emerge when its knowledge claims are challenged by a contingent world. Incapable of adjudicating justified challenges and instituting appropriate changes to its account of reality, Enlightenment projects its own failures on to an external figure or cognitive scapegoat that it blames for the contradictions and problems it itself generates.

This cognitive tendency to project the problems caused by Enlightenment onto an external figure is what explains the immediate relationship between Enlightenment and anti-Semitism in Horkheimer and Adorno's account. Enlightenment, in their view, assumes a number of different forms throughout history. Chief among these forms is modern capitalism and its reduction of economic matters to the value and generation of capital, an economic expression of the Enlightenment's impulse to make the world calculable. Just as through scientific laws "nature ... becomes the stuff ... of mere classification" (Horkheimer and Adorno 2002) and calculation thereby flattening apparent chaos into sameness; so, Horkheimer and Adorno say that "the same equations govern bourgeois justice and commodity exchange ... [bourgeois society] makes dissimilar things comparable by reducing them to abstract quantities" (Horkheimer and Adorno 2002). Thus, like Enlightenment in general, capitalism is a form of domination, since it prohibits persons from living and working in ways that meet their individually determined needs but dictates that "individuals define themselves now only as things [or] statistical elements ..." (Horkheimer 
and Adorno 2002). Moreover, to retain its commitment to profit, capitalism must either overlook the social and economic problems that arise from this form of domination and/or identify an external figure as the essential cause of these problems lest it be forced to compromise what it considers its highest good. According to Horkheimer and Adorno, anti-Semitism is the deflection of capitalism's unresolved issues on to Jews and Judaism. As they maintain, "bourgeois anti-Semitism has a specific economic purpose: To conceal domination in production" (Horkheimer and Adorno 2002). Still, why the Jews?

The answer Horkheimer and Adorno suggest derives from Enlightenment's deepseated "rage against the non-identical that characterizes the totalistic tormenting impulse of Western civilization (Jay 1980). As Martin Jay argues, according to Horkheimer and Adorno, "Jews in their refusal to be assimilated represent an obstacle to the total integration of the dominated world" (Jay 1980). In the Dialectic of Enlightenment, Horkheimer and Adorno suggest that the unassimilability of Judaism is a result of its rejection of the absolute power of concepts to subjugate nature or the objective world as expressed by its prohibition on pronouncing the name of God. Horkheimer and Adorno note how the "disenchanted world of Judaism is reconciled with magic through its negation in the idea of God ... It places all hope in the prohibition on invoking falsity as God, the finite as the infinite, the lie as truth" (Horkheimer and Adorno 2002). Judaism, they say, "brooks no word which might bring solace to the despair of all mortality" (ibid.) and hereby recognizes the perpetual power of a contingent universe to challenge the hubristic attempt to master reality through concepts.

Consequently, when Enlightenment in its form as capitalism seeks a scapegoat, "its rage is vented on those who are both conspicuous and unprotected" (Horkheimer and Adorno 2002), and Jews are the obvious choice. On the one hand, Jews are economically conspicuous. On the other hand, Jews are also outsiders and devoid of political power. "Liberalism" Horkheimer and Adorno explain, "has granted Jews property, but without authority" (Horkheimer and Adorno 2002). Ironically, this unique position generated the impression, particularly to those masses most negatively affected by capitalism's inequities, that Jews have "happiness without power" (Horkheimer and Adorno 2002) and are, unlike those "mutilated by power" (ibid.), free from the guilt of unjust power or the misery of this unjust power's domination.

Fascism is another form of Enlightenment that uses the figure of the Jew as the deflection of its own contradictions, in this case, its leaders' illegitimate claim for absolute power. In Horkheimer and Adorno's view, fascism is an irrational reaction to Enlightenment's domination of nature and a "regression to nature as mere violence" (Horkheimer and Adorno 2002). An attempt to challenge Enlightenment's mastery of nature without the rational tools required to execute this challenge, fascism battles Enlightenment instead of critiquing it, and in this polemical challenge violently replaces competing expressions of Enlightenment domination. As Horkheimer and Adorno state, fascism "seeks to make the rebellion against domination useful to domination" (Horkheimer and Adorno 2002). In so doing, however, fascism must contend with the immediate challenge to its illegitimate seizure of power. Martin Jay explains this and says Horkheimer and Adorno "argued that fascism represented a more naked form of repression than classical capitalism ... fascism is an order of undiluted force led by rulers who long for total possession and unlimited power, at any price ... These megalomaniacal yearnings produce a certain measure of guilt, however, which is alleviated by claiming that is the Jews who in fact crave total control" (Jay 1980). Already marked by capitalism as the scapegoat for its ills, Jews remain the natural choice of targeted antipathy for fascists who present themselves as the antidote to capitalism and who need to deflect their failure to repair these ills and establish legitimate power on these grounds. Taken together, the direct correlation between Enlightenment and anti-Semitism guarantees a tragic encounter between Judaism and the intellectual and institutional products of modernity.

The motor behind these negative outcomes of Enlightenment, including anti-Semitism, is the Enlightenment's insistence upon its status as absolute knowledge, an insistence that ultimately produces its own self-destruction. In its tireless campaign to reduce all human 
reflective activity and its products to the criteria of objectification, Enlightenment "turns against the thinking subject itself" (Horkheimer and Adorno 2002) and the scientific and critical ideas it produces. When absolutized by Enlightenment's impulse towards mastery over contingency, the thought products of the Enlightenment subject are reshaped into determinations of nature and history's fixed laws, and the human agent becomes nothing more than a "shell or an abstract I think" (Horkheimer and Adorno 2002). In the end, Enlightenment dissolves into and is powerless over the very objective order it once came to know, and, in its act of self-destruction, Enlightenment is transformed from a product of reason easily exploited as ideology into a gateway to totalitarianism. As Horkheimer and Adorno explain, "the development of the machine has become that of the machinery of control, so that technical and social tendencies always, intertwined, converge in the total encompassing of human beings ..." (Horkheimer and Adorno 2002).

Ultimately, Enlightenment's self-destruction reveals the illusion of its autonomy or absolute self-subsistence and its inability to thwart ideological forces that aspire to replace rational processes of social coordination. It cannot perdure as absolute, since Enlightenment presupposes the thought content it critiques and, after exhausting all outside content, turns on itself and undermines its own attempt to rationalize knowledge. Thus, to endure, it needs to stand in a conditional and not absolute relationship to a life-world of presupposed claims that constitute the potential subject matter of its review.

\section{Immanent Critique of the Dialectic of Enlightenment}

The notion that Enlightenment reason destroys itself when considered absolute, but can sustain itself when it functions as a finite tool in the service of a life-world, constitutes an immanent critique of Horkheimer and Adorno's analysis. Horkheimer and Adorno cannot generate this critique since they fail to recognize the larger intellectual narrative in which Enlightenment or critique operates and therefore cannot evaluate the limits of Enlightenment in view of this purpose. More specifically, Horkheimer and Adorno collapse the difference between science and Enlightenment. As they state, "Enlightenment ... is the philosophy which equates truth with the scientific system" (Horkheimer and Adorno 2002). Moreover, they mistakenly see this immediate identification of science and Enlightenment as best exemplified in Kant's thought rather than appreciating that the corrective solution implicit in their account is prefigured by Kant and further developed by Hegel.

Unlike Horkheimer and Adorno, Kant recognized the difference between scientific knowledge and critique. The transcendental question is not "how do we know anything at all?" but "what are the conditions of the rational normativity of the knowledge we already take for granted as valid?" which for Kant was Newtonian science. Devoid of this account of the relationship between critique and science, Horhkeimer and Adorno have no standard by which they may evaluate the distortion of Enlightenment as absolute and offer a correction.

Still, many scholars agree with Horkheimer and Adorno that despite the transcendental task, the Critique of Pure Reason offers a fixed account of the rational normativity of determinative judgment. However, this reading overlooks Kant's account of reflective judgment in the Critique of Judgment and its significance for his overall transcendental argument. There, Kant discusses how judgments about beauty do not result from subsumption under an a priori rule but are the product of a community's intersubjectively determined "universal assent" or its sensus communis (Kant 1987). This intersubjectively motivated search for a rule of judgment demonstrates an instance wherein reason does not display absolute certainty but is contingent upon the "common sense" of the community of knowers. Unfortunately, Kant is not explicit about the relationship between reflective judgment and determinative judgment. To find such an account, we may turn to the Phenomenology of Spirit.

The Phenomenology of Spirit offers an immanent critique of Enlightenment. Its debt to Kant's critical common-sense project is already apparent in the Preface where Hegel introduces the idea that this investigation first emerges from the "familiar", or the beliefs 
and habits of mind that a community takes for granted and regards as natural. As Ella Csikos explains, like Reid, Hegel "believe[s] that the starting point should not be a philosophical thesis ... [but] should rest on the confidence in our everyday beliefs and faculties of knowledge" (Csikos 2020). Moreover, also like Kant, the Phenomenology begins, as Robert Pippin says, with an interest in "the conditions of the possibility of knowledge and nowhere seems interested in the modern post-Cartesian problem" (Pippin 1989).

In the Phenomenology, this interest is first represented by the labor of the Understanding or what Hegel describes as "the pure I" that "detaches" thought from the silent immediacy within which "it is actual" (Hegel 1977). According to Hegel, because of its immediacy, the familiar is indeterminate and "is not cognitively understood" (Hegel 1977). Consciousness attempts to determine the contents of the familiar only when it meets with circumstances that signal a problem with this content. In these instances, consciousness seeks to organize its vague impressions and make explicit what it might mean to say that this knowledge is commonsensical. Stated differently, consciousness is committed to doing the work required to keep common-sense knowledge alive and well. As such, the Understanding constitutes the earliest expression of consciousness' effort to identify what may legitimately count as common-sense knowledge. This is why Hegel also says that the Understanding is the "tremendous power of the negative" (Hegel 1977) since it introduces a standard that helps distinguish between beliefs that count as common sense and those that are merely subjective.

Unfortunately, the Understanding overreaches in its attempt to make the standards for the rational normativity of common-sense knowledge explicit and confuses this task with the task of providing an absolute ground of justification for this rational normativity. The Understanding's impulse to discover a single standard of rational validity derives from its immediate relationship to common sense or the familiar. From the perspective of ordinary consciousness, common-sense knowledge appears to be simply the way things are. It would be odd for someone to think that their common-sense beliefs are simply common to themself. If common-sense beliefs are taken as the one correct picture of reality, then it is natural that the Understanding would search for the one correct explanation of this picture. When the Understanding operates this way, it has the tendency to transform shapes of consciousness into ideologies. Nonetheless, the Phenomenology documents how Reason identifies contradictions in these shapes and drives consciousness to reconsider them. Thus, the Phenomenology is the story of the dialectical relationship between the Understanding and Reason when it is Reason that works to protect common sense or the experience of ordinary consciousness from erasure by the Understanding, which runs the risk of asserting a standard of rationality removed from the experience of ordinary consciousness. Ultimately, the Understanding continues its quest to identify a single and absolute standard of rationality until it becomes clear to consciousness that instead of laboring to identify what counts as common sense for the sake of preserving common-sense knowledge, the Understanding's assumption that it may identify an absolute standard of rationality leads the Understanding to position itself as the final arbiter over any and all knowledge claims.

This is the position consciousness reaches as "insight" or Enlightenment. At this stage, consciousness has ruled out all prior hypotheses and recognizes them as determinations of the Understanding or the pure I. More specifically, the Phenomenology diagnoses Enlightenment in the context of its alienation from the culture of Sittlichkeit and demonstrates Reason's interest in resolving this condition of alienation. The discussion of Sittlichkeit examines consciousness' theory that custom grounds the rationality of knowledge, but it fails because it cannot account for the impact of the individuals who live by and respond to it. In response, consciousness posits that "though alienated from the power of her community, the individual issues value judgments about the wealth and power of the state [to contribute to] the development of a culture of one or the other ..." (Hegel 1977). Ultimately, however, neither expresses the universal since both are products of these individual, subjective judgments. 
All is not lost however since in the dissolution of culture as a stable site of the universal, consciousness discovers the critical self who recognizes the contradiction in culture and "knows how to ... to pass judgment on it ..." (Hegel 1977). Thus, the move into Enlightenment arises when, in the act of issuing negative judgments regarding culture, the self retreats from its prior world of custom and takes itself to be the site of the universal. As Hegel says, "in the might of its negativity, [it] eliminates everything objective that supposedly stands over against consciousness ..." (Hegel 1977). Enlightenment's notion of the rational slf is tantamount to the assertion of the Understanding without its accompanying hypotheses as itself, the new hypothesis. As the pure I, it allows its own insights to replace the affirmations of ordinary consciousness, which it originally sought to preserve.

According to the Phenomenology, there are two aspects to the pure self's alienation from culture's content. First, there is the pure self as insight or the skepticism that rejects all knowledge content other than its own contributions. Second, the retreat into the pure I produces its own thought content in "faith." Together, insight and faith represent the vexed and alienated relationship of the pure self with the content of culture or common-sense knowledge. The tension between them manifests in the internal contradiction of the pure self, which needs the content of common-sense knowledge as the object of its critique and needs to affirm itself as the agent of rational insights, but is also the exercise of absolute critique that refuses to admit the success or rational value of any existing knowledge content and affirms only its own negation of it.

Of the two facets of the pure self, it is insight that most closely resembles Horkheimer and Adorno's profile of Enlightenment. Like Enlightenment, insight takes itself to be an absolute end in itself that, as Stephen Houlgate explains, "aims to make everything rational" (Houlgate 2012). First, insight imposes itself on culture and then on the contents of faith. In the language of Horkheimer and Adorno, insight shows the believer that she is the source of her own apparently universal content and attacks the contents of her beliefs as "superstitions, prejudices and errors" (Horkheimer and Adorno 2002).

Insight wins in its battle against faith. In the end, however, it attacks and destroys itself as well. Like the Dialectic of Enlightenment, the Phenomenology documents the irrationality and hence self-destructiveness of Enlightenment self-promotion as the absolute standard of knowledge that rejects all content as inadequate to this standard. However, unlike the Dialectic of Enlightenment, the Phenomenology also shows that insight's self-destruction is more than a result of its absolute drive for mastery but a reflection of its unresolved alienation from culture or the thought contents of its life-world. As critique, insight needs content as the object of its negations. Nonetheless, as the pure negative, it rejects all thought content, even its own rational affirmations and those of other rational selves. As Hegel says, insight is the "absolute negation of itself" (Hegel 1977). Thus, insight's character as critique undermines its self-defined purpose to promote itself by spreading its positive affirmations throughout culture and religion. However, in so doing, insight acts as a subjective agent that rages against the productive activity of a rational community, and its unregulated campaign to promote itself unravels in self-contradiction.

Hegel's analysis of Enlightenment parallels many features of Horkheimer and Adorno's. Both recognize that Enlightenment's assertion of itself as the absolute ground of knowledge is tyrannical and self-destructive. Nonetheless, the two accounts differ with regard to their assessment of the relationship between Enlightenment and ideology. In Horkheimer and Adorno's account, Enlightenment is frequently deployed as ideology to suppress ongoing, individual, and communal responses to changes in history. Additionally, Enlightenment's self-destruction explains how ideology easily steps in to replace reason's role as the instrument of social coordination. By "social coordination", I mean a community's ability to operate collectively. Social coordination presupposes justification of proposals as legitimate options through collective reason. However, if reason is weakened, ruling powers are all too happy to appeal to ideological world-views that offer a short-cut approach to the process of vetting proposals for social action, and those governed by them will often accept this appeal given the lack of a rational alternative. This is the situation that results 
from Horkheimer and Adorno's analysis of Enlightenment, since they do not show how Enlightenment reason can be repaired.

By contrast, the Phenomenology offers an immanent critique of this notion of Enlightenment that provides a workable account of collective reasoning practices that can undergird social coordination and offset the potential threat of ideological substitution. This is because the Phenomenology situates its analysis of the Enlightenment within the original context of an established relationship between critique and common sense as presented in the Preface, and, as the agent of this task, consciousness continues to search for means by which it may be completed.

Applied to the current stage, consciousness reasons that if the Enlightenment self fails because it takes itself to be unconditioned over all knowledge content, then, to exist, it needs to stand in a relationship with or be mediated by a pre-existing body of knowledge. Enlightenment is contingent upon knowledge content in two ways. First, as critique, the pure self presupposes a pre-existing body of knowledge claims to critique. Without them, Enlightenment turns its activity of critique on itself and destroys its own insights. Second, in order to avoid self-contradiction, the Enlightenment self needs to presuppose the perdurance of its own rational insights and the rational insights of other rational agents. Recall that the original goal of Enlightenment is to spread its own rational claims. If, however, these rational claims are declared unjustified by a critique that takes its own attacks as the only valid source of rational thought, then Enlightenment as absolute critique undermines Enlightenment as the determination of rational affirmations. Taken together, the pure self presupposes a body of knowledge or life-world contents, many of which are already vetted and working and some of which occasion rational reflection regarding the conditions of their validity. As such, Enlightenment needs to be responsive and not self-promotional and not self-justifying.

Consciousness' immanent critique of the Enlightenment also uncovers the identification of the pure self of insight with the intersubjective or communal Subject. If the pure self needs to concede the existence of rational affirmations, it must also concede the existence of other rational agents who generate them. Insights that are not intersubjectively affirmed are merely subjective contributions or the very opposite of what the Enlightenment prides itself on providing. Thus, to exist, the rational self must be a communal Subject that intersubjectively reflects upon the conditions of the objective validity of the knowledge claims that this communal Subject relates to, uses, and seeks to preserve.

No doubt, like the Enlightenment self, the communal Subject has the authority to issue determinations concerning the rational validity of knowledge claims. However, what distinguishes this communal Subject from the pure self of the Enlightenment is not only its communal constitution but its relationship to the knowledge claims of its life-world. Like the believer, the communal Subject recognizes the "unity of itself as unity of self and object ..." (Hegel 1977), i.e., it recognizes that life-world claims constitute the site of the universal, which the communal Subject helps identify and generate. Like the believer, the communal Subject has a vested interest in the Absolute or knowledge content. However, unlike the believer, the communal Subject also recognizes that its thought content often requires the labor of a critical investigation into the conditions required to sustain the rational validity of these claims. In short, the communal Subject's relationship to knowledge content is best described as the community's form of life. Thus, the community's interest in its knowledge content derives from its use of this content as the community exists and develops in and through the changing conditions of history.

Taken together, Hegel's analysis stages a pathway forward beyond Horkheimer and Adorno's account. More specifically, it teaches us that Enlightenment is justified when it works for the life of this community and not as an end in itself. Additionally, consciousness' insights regarding critique as an activity that works on behalf of a community's form of life is at the same time consciousness' enriched determination of the Understanding itself whose activity is now appreciated in the context of the life of the intersubjective Subject in its relationship to what it takes to be its common-sense knowledge. 
In the Phenomenology, consciousness does not immediately arrive at an awareness of the community's form of life as the authoritative subject of its rational self-determination. Instead, it first posits a communal Subject that "knows duty to be [the] absolute essence", (Hegel 1977) which however stands in an antinomous relationship to nature. In its wake, consciousness identifies the imperfect, yet knowable, reality of the real subject who affirms and acts on her own convictions of conscience in concert with "I"s who seek each other's recognition. Thus, the subject as conscience "knows its inner voice ... to be a divine [one]" (Hegel 1977) and part of a community with others who have the same voice and make the same contribution to this universal.

Unfortunately, the romantic self refuses to act in the world. Despite this, it persists since, in fleeing the world, it performs a judgment against others who do not flee but take for granted other criteria of rationality beyond the convictions of the individual soul herself. The romantic self's rejection of the world turns out to be a mode of relating to the world, since a critic is always parasitic on the object of her critique. Moreover, since the romantic self's act of criticism issues a silent judgment against others, her position proves to be hypocritical, since it presupposes the expectations of others about what makes sense. Only in light of these expectations is the romantic self's act understandable as a judgment. The romantic self's intervention presupposes a "common sense criterion of intelligence and rationality ..." (Hegel 1977). The community itself recognizes his hypocrisy.

Nevertheless, the romantic self correctly denounces the corresponding hypocrisy of the community, whose members take their common-sense assumptions as universal law. The ironist's critique makes it clear that if there are communally shared common-sense standards of what "counts", these are products of particular convictions subject to processes of community recognition and are neither fixed nor metaphysically grounded.

At this juncture, consciousness realizes that the Subject is a community that sustains agreement with respect to what counts as commonsensical or intelligible. If it did not, individual members would not be able to make judgments without perpetually falling prey to the skeptic's challenge. Still, this community is constituted by finite individuals who live within the constraints of history and nature. Taken together, the community is the Subject whose identity depends upon its shared beliefs about rational intelligibility as these standards are continually recalibrated in relation to changing times and circumstances.

\section{Ideology's Challenge to Communal Justificatory Reflection}

With this account, we can see how the Phenomenology's immanent critique of Enlightenment provides a restored vision of reason as a communal praxis of justificatory reflection by means of which knowledge claims and the societal institutions that develop and deploy them can be preserved as rational and thereby sustain legitimacy. Communal justificatory praxis constitutes the primary means by which a community determines if and when theoretical or practical acts "make sense" and is therefore an instrument of social coordination and societal legitimization. Hegel's account therefore not only challenges Horkheimer and Adorno's association of Enlightenment with ideological forces that seek to blunt reasoning processes but Horkheimer and Adorno's account of the destruction of these reasoning practices altogether that leaves room for ideological forces to replace them as the determinants of social coordination.

The analysis here reflects the account of reasoning as a social praxis that many others such as Pippin, Pinkard, and Houlgate have also celebrated. Moreover, in my recent book, Nature and Norm, I have maintained that awareness of the rational authority of the community to preserve the common-sense standards of its form of life constitutes an imperative to exercise this authority. There, I demonstrate how a failure to do so guarantees the decay of rationally vetted life-worlds and the retention of meaningless and polemical claims that have not been rehabituated in accordance with the common-sense standards of the authoritative community (Rashkover 2020).

In Nature and Norm, I also demonstrate the importance of this account for Jewish thought. More specifically, I show how modern Jewish communities and thinkers expe- 
rience a process of coming to terms with modern science such that, like consciousness in the Phenomenology, they no longer take for granted natural science's rational self-evidence and allow it, like Horkheimer and Adorno's Enlightenment, to critique and undermine Jewish claims. Instead, in ways that parallel consciousness' inquiry into rationality, modern Jewish thought comes to apprehend the role of the community as it encounters a changing world in the determination of rationality and applies this dynamic standard to its own life-world claims (Rashkover 2020). Ultimately, the Hegelian account of communal, rational self-reflection offers Jewish communities a reason to sustain confidence in contemporary Enlightenment-spawned institutions and in their ability to remain immune from forces of ideological encroachment and from the persistent anti-Semitism that, according to Horkheimer and Adorno, is linked to them.

However, unfortunately and all too frequently, scholarly appreciation for Hegel's repair of Enlightenment reason fails to recognize the vulnerability of this communal philosophical praxis to ideology. At the heart of communal justificatory activity is a central paradox that guarantees its vulnerability to replacement by the forces of ideology. As I will show, this vulnerability to ideology is a problem for Jewish and non-Jewish contemporary communities alike.

As I have argued, communal justificatory reflection or the praxis of critical common sensism provides a means by which social coordination and the legitimization of societal institutions can be achieved. Moreover, we saw that, to exist, Enlightenment must take for granted that many or indeed most life-world claims do not prompt skeptical concern but operate as accepted examples of common-sense standards determined by the community. Critical common sense I argued, is not proactive, but a response to a community's ongoing encounter with a range of contingencies that can alter the current status of one or more of its life-world claims. Thus, while communal justificatory praxis is the ultimate arbiter of common sense and therefore the authoritative source for the principles of social coordination, in reality, social coordination is more immediately a product of the success of this praxis as manifest in the body of already justified and currently accepted life-world beliefs. Rationally based social coordination operates most successfully in times of life-world stability when members of a community can easily deploy shared beliefs in the confidence that they are widely accepted according to taken-for-granted common-sense standards.

Consequently, communal justificatory reflection is needed only when one or more persons in the community cast legitimate doubt on the common-sense validity of one or more life-world claims. Philosophical activity steps in precisely when the community fails to agree upon the common-sense standards that govern a belief or set of beliefs that are vital to social coordination. If, however, rationally supported social coordination draws from the stability of already vetted life-world beliefs, it follows that rationally motivated social coordination is most fragile precisely in moments when the reconciliatory praxis of communal justification or philosophical activity is most in demand. The more philosophical activity is needed to support social coordination and the legitimization of societal acts and institutions, the more the community is vulnerable to ideological attempts to replace reason as the chief determinant of the principles of societal action. Stated otherwise, Hegel's immanent critique of Horkheimer and Adorno's account of the Enlightenment may have salvaged reason, but the reason it has restored operates in response to contingency and is therefore always threatened by ideological short cuts. These short cuts pretend to offer rational justification for societal acts but nullify the role of communal reflection and permit the slow and steady dissolution of public reasoning processes that shore up a community's adaptive and non-alienated relationship to its changing world. Unfortunately, there are a vast number of contingencies that can easily destabilize life-worlds by altering the environment within which communities operate and therefore the conditions of the intelligibility of claims. Surely wars and natural catastrophes come to mind, but demographic changes together with increased cultural pluralism and diversity can also create adequate conditions for life-world instability and threaten the ability of justificatory processes to effectively restore the common-sense grounds of social coordination. 
By exposing the inevitable fragility of communal justificatory reflection, I do not mean to suggest that this work is somehow less valuable than the ideological systems that seek to replace it. No doubt, philosophical activity takes time, but it is time well spent, as it is the only means by which a community can safeguard the decay into meaninglessness or polemicism of its form of life and offer rational justification for social actions and institutions. By contrast, ideologies permit the retention of irrational ideas that are no longer commensurate with the authoritative and pragmatic needs of a community as it contends with a changing world. Thus, ideologies have a shorter life span since, in the long run, they are inevitably refuted by common sense. In the short term, however, the very crises that activate high levels of philosophical reflection also often demand immediate attention and practical response. This is often the case with respect to political decisions, the urgency of which often lends itself to the ideological substitution.

Arguably, critical common sense and ideology are each other's greatest antagonists. If the conditions that prompt reflective praxis are also the conditions under which a community is most vulnerable to ideology, it is also the case that ideology presents itself as a pseudo form of rationality because those who deploy it seek the rational legitimization uniquely provided by the work of communal justificatory reflection. The stakes of the struggle between an Hegelian repair of the absolutism of the modern Enlightenment and ideological world-views that undermine communal philosophical agency are high, not only for contemporary American society but for Jewish communities as well.

Like other communities, Jewish communities need to reflect upon the extent to which they do or do not allow their actions and beliefs to be anchored by the communal praxis of reflective judgment or by ideological positions. Jewish communities in the United States are particularly vulnerable to ideology when they experience periods of significant life-world crises that render the determination of social coordination rooted in communal justificatory reflection more burdensome and when these same communities confront and are lured by the ideological forces of late capitalism that offer an alternative route for achieving communal coordination.

There are noteworthy differences between the 19th century capitalism that Marx and others critiqued and the late capitalism that ideologically threatens to replace Jewish communal justificatory reflection as the mechanism for Jewish social coordination. In an essay entitled, "Ideology", Jurgen Habermas offers a detailed analysis of these key differences and a portrait of how late capitalism operates as a form of ideological encroachment upon rational life-world processes.

According to Habermas, in advanced capitalist societies, the state operates as an ideological force. Characteristic of late capitalism, he argues, is a "permanent regulation of economic processes by ... state intervention ... as a defense mechanism against the dysfunctional tendencies which threaten the [capitalist] system" (Habermas 2014). At first glance, the welfare state might appear to offer real solutions to capitalism's problems. However, Habermas argues that state intervention props up late-stage capitalism instead of exposing it to socio-political objections that call for systematic corrections. As Habermas maintains, the state "provides a guaranteed minimum level of welfare which offers secure employment and a stable income ... to maintain stabilizing conditions for an economy that guards against risks to growth ..." (Habermas 2014).

Thus, the welfare state in late capitalism is an ideological force since "the government's action" is not directed to resolving the contradictions and issues caused by capitalism but "is directed toward the economic system's stability and growth [such that] politics now takes on a peculiarly negative character" (Habermas 2014). By this Habermas means that when the state works as the handmaiden of the capitalist system, it disregards the practical questions of its citizens. In this role, the state only needs the support of economic and technological experts and systems, and since, as he says, "the solution of technical problems is not dependent on public discussion ... the new politics of state intervention requires a depoliticization of the mass of the population ..." (Habermas 2014). Thus, the welfare state operates as an ideological force for the sake of a ruling power, albeit a sizable one, since 
advanced-stage capitalist societies demonstrate little regard for their members' political interests and practical problems and "open conflicts about social interests break out with greater probability the less their frustration has dangerous consequences for the system" (Habermas 2014).

Moreover, according to Habermas, the dominance of the welfare state in its role as handmaiden of capitalist success not only encroaches upon the deliberation over practical problems in the political arena but "the moral realization of a normative order [which is] a function of communicative action oriented to shared cultural meaning ... is increasingly supplanted by conditioned behavior [as well] ..." (Habermas 2014). In the language used above, the social coordination of community actions are steered by the demands of techno-economic solutions that safeguard capital and not by the rationally reflective communicative labor of life-world members who draw from and assess their pools of cultural traditions to determine choices of collective action.

In the contemporary American context, Jewish communities of a variety of denominational affiliations are experiencing life-world crises, albeit to different degrees and with respect to a range of different Jewish claims and norms. As discussed earlier, it is normal that, over time, claims and norms once taken to be common sensical no longer immediately appear as such. Communities have little difficulty working with these claims to either establish new ways of interpreting them in relation to other claims they hold or allowing these claims to enter into temporary or permanent disuse. Problems arise when the number of such claims mounts and communities must devote substantial energy to the rehabituation of their life-world. Thus, as noted above, conditions that call into question the common-sense status of a significant number of particular claims simultaneously provoke communal justificatory reflection and vulnerability to ideological forces. Communal justificatory reflection is labor intensive, takes time, and often renders ongoing social coordination difficult to achieve. Under these circumstances, Jewish communities in the United States easily fall prey to the specific ideological forces of late capitalism.

Communities that are most vulnerable to ideological forces display three dominant features. First, they demonstrate a superficial or merely rote retention of life-world claims and norms that they are unwilling to re-habituate. Second, they demonstrate an overarching desire to sustain their form of life, despite the plausibility challenges they currently face. Third, the first two features give rise to a willingness to outsource the work of securing the continuity of the life-world to an external individual or group who apparently "interprets" the meaning of life-world claims but, in fact, replaces the community's reflective activity with a fixed ideological view that claims to offer the true meaning or essence of the lifeworld and its attending claims. A community that permits itself to outsource the work of securing its own future denies the authority of its own common-sense determinations. While there are a multitude of examples of this vulnerability to ideologization, by way of conclusion, I want to focus on one particular example that illustrates the above features.

In an interview with Tablet magazine in 2020 (Cooper 2020), Stosh Cotler, then CEO of an organization called Bend the Arc, stated that "at this point in time we're really seeking to become the institution that redefines the center of gravity in the American Jewish community... We have a vision and an agenda that we believe to now be the communal agenda of the Jewish community" (Cooper 2020). Who is Bend the Arc? and how and why could it be charged with the right and/or authority to set the agenda for the Jewish community?

According to the article in Tablet, Bend the Arc is the "Jewish" part of a "larger progressive political coalition bringing top down messaging to synagogues and organizations and providing the validation of Jewish support upstream" (Cooper 2020). As such, Bend the Arc is a satellite organization designed to further the power of progressive political positions within the American political scene. Not surprisingly, Bend the Arc's primary issues have to do with the advancement of progressive proposals designed to influence the state as it currently exists in this late-capitalist period. Regardless of its left-leaning approach to the American political issues, BTA takes for granted and seeks to shape the nation state 
as it exists in this particular form. Consequently, BTA presupposes and participates in late-capitalist political ideology and attempts to package this ideology as the key to Jewish preservation in order to acquire Jewish political support for its progressive political work. As Cotler says, BTA wants to use Jewish communities to "remake America [into a nation] where political power can be used to recalibrate and provide more justice" (Cooper 2020).

As such, BTA operates as an ideological substitute for the activity of justificatory communal reflection necessary for the long-term preservation of Jewish life-worlds. As Cotler admits, BTA has flourished among "disenchanted Jews" (Cooper 2020), and BTA is the vehicle through which American Judaism can be revitalized. It is, as I have argued, natural for communities to seek out new ideas and new accounts of older claims. Moreover, contrary to the diagnosis presented by Horkheimer and Adorno, Jewish communities have the rational resources they need to preserve themselves in the contemporary world. Ideological substitutions like BTA's progressive politics cannot provide long-term resources for Jewish continuity since, as ideological, BTA's world-view is fixed and resistant to rational consideration of its claims as these claims are confronted by the experience of persons in a changing world.

Nonetheless, Jewish communities undergoing life-world crises will often find the labor of rational rehabituation too demanding and permit themselves to outsource the task of life-world reinterpretation. In these moments, organizations like BTA are there, ready and willing to offer essentializations of Jewish life-worlds that appear meaningful to disenchanted Jews. In their willingness to replace autonomous processes of Jewish communal self-reflection, ideological organizations like BTA act as external sources of hermeneutical authority over Jewish communities. Cotler is not shy about BTA's willingness to assume this role, and she says that she sees BTA as "mirror that we're holding up to American Jews, and to mainstream communal institutions ... [in order] to say that we reflect and represent what the majority of American Jews believe ..." (Cooper 2020). As Rabbi Sharon Brous, a rabbi affiliated with BTA, puts it, "to claim that the affairs of the market, the cost and nature of healthcare for the poor ... and a living wage ... [are] outside the scope of religion is to strip religion of its essence" (Brous 2017). No doubt, Jewish life-world ideas and norms have material and political implications. The question is not whether they do or do not but rather who makes the determinations concerning these implications and whether or not these determinations are ideological or products of rational reflection.

In conclusion, there is little doubt that Hegel's repair of Enlightenment alerts all of us to the character of a non-absolute reason that serves the authority of communities and their forms of life and does not in itself singularly give way to exploitation by forces of tyranny or totalitarianism. This Hegelian immanent critique of the dialectic of the Enlightenment offers Jewish communities good reason to remain confident in the institutional structures and intellectual climate of the contemporary Western world. If, however, this Hegelian repair illuminates the ongoing power of reason in contemporary society, it does not wholly disable ideological forces that not only threaten to shape political, scientific, and academic institutions but also threaten to replace the critical autonomous labor of reflection that Jewish communities can and should avail themselves of in their ongoing commitment to the preservation of their life-worlds.

Funding: This research received no external funding.

Institutional Review Board Statement: Not applicable.

Informed Consent Statement: Not applicable.

Data Availability Statement: Not applicable.

Conflicts of Interest: The author declares no conflict of interest. 


\section{References}

Arendt, Hannah. 1953. Ideology and Terror: A Novel Form of Government. The Review of Politics 15: 303-27. [CrossRef]

Brous, Sharon. 2017. What You Call Politics We Call Torah. The Jewish Journal. Available online: https://jewishjournal.com/ commentary/opinion/221286/call-politics-call-torah/ (accessed on 31 October 2021).

Cooper, Sean. 2020. Bending the Jews. Tablet. Available online: https://www.tabletmag.com/sections/news/articles/bend-the-arc (accessed on 31 October 2021).

Csikos, Ella. 2020. Common Sense and Speculation: Reid and Hegel on Immediate Certainty. Available online: https://www.academia. edu/8011410/Common_Sense_and_Speculation_Reid_and_Hegel_on_Immediate_Certainty (accessed on 31 October 2021).

Eagleton, Terry. 2014. Ideology. London: Routledge.

Habermas, Jurgen. 2014. Ideology. In Ideology. Edited by Terry Eagleton. New York: Routledge, pp. 190-201.

Hegel, Georg Wilhelm Friedrich. 1977. The Phenomenology of Spirit. Translated by A. V. Miller. Oxford: Oxford University Press.

Horkheimer, Max, and Theodore Adorno. 2002. Dialectic of Enlightenment. Stanford: Stanford University Press.

Houlgate, Stephen. 2012. Hegel's Phenomenology of Spirit: A Reader's Guide. New York: Bloomsbury.

Jay, Martin. 1980. The Jews and the Frankfurt School: Critical Theory's Analysis of Anti-Semitism. New German Critique 19: 137-49. [CrossRef]

Kant, Immanuel. 1987. Critique of Judgment. Translated by Werner S. Pluhar. Indianapolis: Hackett Publishing.

$\mathrm{Ng}$, Karen. 2015. Ideology Critique from Hegel and Marx to Critical Theory. Constellations 22: 393-404. [CrossRef]

Pippin, Robert B. 1989. Hegel's Idealism: The Satisfactions of Self-Consciousness. Cambridge: Cambridge University Press.

Rashkover, Randi. 2020. Nature and Norm: Judaism, Christianity and the Theopolitical Problem. Boston: Academic Studies Press. 